\title{
Os Valores da Economia Solidária ${ }^{1}$
}

WCAS RODRIGUES AZAMBU A*

\section{Resumo}

Na perspectiva de Paul Singer sobre a autogestão, está implícita uma relação de co-determinação entre a realização de práticas autogestionárias e a incorporação de valores ideológicos de Economia Solidária por parte dos trabalhadores. Este estudo critica essa relação de co-determinação a partir da fundamentação empírica de 42 entrevistas com trabalhadores de duas cooperativas de produção. Assim, identificou-se uma heterogeneidade de valores ideológicos, definida em três perfis: perfil de solidariedade, perfil de assalariamento e perfil de instrumentalização capitalista. Argumentamos que a existência desses perfis não pode ser explicada pelo modelo de co-determinação de Singer e, em contrapartida, propomos uma explicação baseada nos estudos sociológicos e de psicologia social sobre os valores de trabalho.

Palavras-chave: Valores ideológicos. Economia solidária. Autogestão. Cooperativismo.

* Mestre em Sociologia pela U niversidade Federal do Rio Grande do Sul (UFRGS) e colaborador do grupo de pesquisa Trabalho na Sociedade Contemporânea.

1 Este artigo é baseado em nosso trabalho de conclusão do curso de graduação em Ciências Sociais da Universidade Federal do Rio Grande do Sul. 


\section{Introdução}

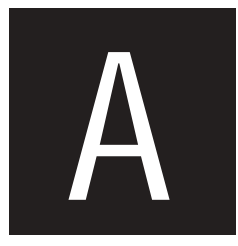

partir da década de 1980, e especialmente na década de 1990, alguns autores (SIN GER, 2003; MANCE, 1999; GAIGER, 1996; LAVILLE, 2004; RAZETO, 1997) vêm destacando a expansão e desenvolvimento de iniciativas econômicas que compõem a chamada Economia Solidária. As causas apontadas para explicar este crescimento são, de um lado, as transformações que ocorreram no mundo do trabalho, a partir da década 1970, com a crise do modelo fordista-taylorista de produção, que resultaram em aumento dos processos de exclusão do mercado formal de trabaIho (desemprego, flexibilização e precarização das relações de trabalho) e, de outro, com a crise do Estado de Bem-Estar Social e a queda do bloco soviético, a ascensão do projeto neoliberal cujas políticas estariam aumentando os processos de exclusão social e, assim, provocando o crescimento da pobreza junto ao desmanche dos mecanismos de proteção social (previdência, serviços públicos, etc.). Assim, as iniciativas de Economia Solidária atingem aqueles que estão excluídos ou em vias de exclusão do mercado formal de trabalho e, também, pessoas historicamente excluídas pertencentes às classes populares, que buscam alternativas para geração de renda. Essas iniciativas assumem diversas formas: cooperativas que atuam nos vários setores da economia (produção, consumo, serviços, etc), pequenas empresas de caráter familiar e/ou comunitário, bancos populares, clubes comunitários de troca, entre outras ${ }^{2}$. Diante desta diversidade, no Brasil, o que diferenciaria os empreendimentos solidários das demais iniciativas que surgem pelas mesmas razões estruturais mencionadas acima,

2 Para um panorama dessas iniciativas econômicas, ver França Filho e Laville, 2004: 150-158; Singer, 2002a: 39-108. E para uma rápida e precisa definição de algumas delas, ver Pinho, 2004. 
seria o fato de que elas estariam organizadas sob a forma da autogestão. São, portanto, iniciativas cujos participantes detêm a posse coletiva dos meios pelos quais exercem a atividade econômica (produção, consumo, poupança, etc.) e, por isso, são igualmente responsáveis pela gestão do empreendimento, através do princípio "um membro igual a um voto".

Para Singer (2000a, 2000b), a experiência de trabalho autogestionário traz consigo um potencial educativo, ou seja, a autogestão, através das práticas que a envolvem, permitiria educar e transformar o comportamento dos sujeitos, no sentido de que suas ações passassem a ser pautadas por valores ideológicos que não aqueles das relações sociais capitalistas. Portanto, para Paul Singer, a constituição de empreendimentos autogeridos não seria apenas uma alternativa encontrada pelos trabalhadores ao assalariamento e à pobreza, mas um conjunto de práticas que podem transformar a consciência e o comportamento dos seus praticantes, fazendo com que esses últimos incorporem valores ideológicos (participação, igualdade, solidariedade, etc.) opostos àqueles que fundamentam a lógica individual e competitiva das sociedades capitalistas.

Enfim, podemos dizer que, de forma implícita, Singer sugere uma relação de co-determinação entras as práticas de trabalho autogerido e os valores ideológicos de Economia Solidária, que pode ser mais ou menos expressa da seguinte maneira: à medida que o sujeito se envolve nas práticas econômicas de autogestão, ele é educado para a autogestão e à medida que ele é educado, mais ele pratica e incorpora os valores da autogestão que, por conseguintes são os valores ideológicos da Economia Solidária.

No nosso entender, a perspectiva de Singer, segundo a qual o modelo de autogestão possuiria práticas e condições necessárias para que os trabalhadores incorporassem os valores ideológicos de Economia Solidária, não é capaz de compreender apropriadamente a relação entre autogestão e valores daqueles que se encontram no seio de um empreen- 
dimento autogerido. Principalmente porque essa visão ignora que outras orientações ideológicas podem surgir no seio do empreendimento autogerido.

Neste sentido, o presente estudo teve como principal objetivo investigar e refletir sobre a existência de diferentes valores ideológicos expressos por trabalhadores de duas cooperativas de produção autogestionárias. Deste modo, procuramos discutir a relação de co-determinação estabelecida por Paul Singer entre autogestão e valores ideológicos de Economia Solidária, bem como delinear uma outra perspectiva para interpretação da relação entre autogestão, valores e princípios dos trabalhadores com base no conceito de ideologia de M artin Seliger (1976) e nos estudos sociológicos e de psicologia social sobre valores de trabalho.

Este artigo, então, está estruturado da seguinte maneira: 1) Perspectivas sobre Economia Solidária - nesta seção iremos expor brevemente algumas interpretações sobre o fenômeno da Economia Solidária, mostrando que somente em Singer o modelo de autogestão assume uma centralidade teórica. 2) Cooperativismo autogestionário - nesta parte, trataremos de definir o que são as cooperativas autogeridas e a relação de co-determinação que Paul Singer estabelece entre autogestão e valores ideológicos de Economia Solidária. 3) Valores Ideológicos - explicitaremos a noção que utilizamos neste estudo de valores ideológicos e o modelo de interpretação sobre esses últimos que podemos vislumbrar através dos estudos sociológicos e de psicologia social sobre valores de trabalho. 4) Os Perfis Ideológicos - mostraremos a heterogeneidade ideológica entre os trabalhadores através da definição de perfis ideológicos, a saber, perfil de solidariedade, de assalariamento e de instrumentalização capitalista e, 5) Considerações Finais - à luz dos resultados de nossa pesquisa empírica e com base na perspectiva teórica por nós adotada, discutiremosa perspectiva de Singer sobre a relação entre autogestão e valores ideológicos dos trabalhadores. 


\section{Perspectivas sobre Economia Solidária}

Como foi mencionado, a partir da década de 1970, a crise do modelo fordista-taylorista de produção e o desmanche dos mecanismos de proteção social (Previdência e serviços públicos) promovido pelo avanço das políticas neoliberais, produziram prejuízos às condições de vida dos trabaIhadores e de setores mais pobres da população. Tais prejuízos fizeram com que estes últimos organizassem uma série de iniciativas econômicas para geração alternativa de trabalho e renda, tais como: cooperativas, empresas autogeridas, sistemas de trocas não-monetárias, bancos populares, entre outras. Neste contexto, teóricos e militantes políticos vislumbraram nestas iniciativas econômicas a possibilidade da construção de alternativas aos novos desafios do mundo do trabalho e até mesmo à organização social capitalista. É neste processo que, então, é formulada a noção de Economia Solidária, isto é, tal noção representa o esforço de alguns pensadores em não só compreender a lógica de certas iniciativas de geração alternativa de trabalho e renda, como também, identificar nelas o potencial para resolução dos problemas gerados pela crise do fordismo e do Estado de Bem-Estar ou, ainda, perceber nessas iniciativas as bases para superação da sociedade capitalista enquanto tal.

Todavia, a noção de Economia Solidária não é a única que foi elaborada por aqueles que se interessaram por tais iniciativas. Assim, encontraremos na literatura outras noções como: economia popular (ICAZA e TIRIBA, 2003; KRAYCHETE, 2000), economia do trabalho (CORAGGIO, 2000, 2003), terceiro setor ou setor não-lucrativo (SALAM O N e AN HEIER, 1997), economia social (FAVREAU, 2005), entre outras. Mas, mesmo entre os acólitos da noção de Economia Solidária há discussões sobre sua definição e que tipo de alternativa que ela representa. Por exemplo, Razeto (1997) entende a Economia Solidária como um processo constante e difuso 
de inserção de práticas econômicas de caráter solidário no seio da estrutura econômica atual, isto é, a solidariedade como força transformadora da Economia desde dentro desta, resultand o em uma nova racionalidade econômica. Com isso, Razeto está querendo distinguir-se da visão filantrópica que entende a solidariedade como um mecanismo separado da Economia, que serviria para atenuar os efeitos negativos desta última. "Lo que sostenemos es[... ] que la solidaridad se introduzca en la economía misma, y que opere y actue en las diversas fases del ciclo económico, o sea, en la producción, circulación, consumo y acumulación" (RAZETO, 1997: 14). Nesse sentido, Razeto defende a idéia de identificar os diversos meios pelos quais é possível (na e a partir da formação econômica capitalista atual), inserir a solidariedade nas práticas econômicas. Assim, ele quer evitar uma completa oposição entre Economia de M ercado e Economia Solidária:

La idea y proyecto de una economía de solidariedad no los pensamos como negación de la economía de mercado o como alternativa frente a la economía de empresas. Hacerlo sería completamente antihistórico e incluso ajena al hombre tal como es y como puede ser. (RAZETO, 1997: 17).

Assim, para Razeto, a Economia Solidária seria um projeto por construir, mas sem um modelo predefinido, ou seja, não existe uma fórmula de incorporação da solidariedade no fazer econômico e, sim, diferentes formas que interagem entre si, podendo até mesmo convergirem, acentuando esse processo de incorporação da solidariedade. Estas formas são elaboradas e realizadas pelos próprios atores sociais, por isso a importância, segundo o autor, em mostrar as vantagens da solidariedade na Economia e, assim, fazer com que mais e mais pessoas estejam engajadas e comprometidas neste processo de inserção da solidariedade na Economia.

De maneira diferente, mas também não propondo uma completa oposição entre Economia de Mercado e Economia Solidária, podemos 
identificar a visão de Jean-Louis Laville. A importância da Economia Solidária, para este autor, é que ela nos obriga a pensar o econômico para além dos princípios de mercado:

No lugar, portanto, de resumirmos a economia ao mercado, parece-nos preferível [...] admitirmos que, em relação ao conjunto das práticas que conformam a dinâmica econômica mais ampla, existem diferentes princípios de interação [...]. É exatamente esse olhar ampliado da dinâmica econômica mais geral que nos permitirá entender [...] o processo singular de uma economia solidária, que tende a reunir diferentes lógicas. (FRANÇA FILH O; LAVILLE, 2004: 17)

Laville, então, baseia-se em Karl Polanyi para distinguir três princípios de organização da atividade econômica: 1) o do mercado, baseado na livre concorrência entre indivíduos auto-interessados; 2) 0 da redistribuição, segundo o qual a esfera da produção deve remeter-se a uma autoridade central que se encarrega da distribuição dos bens; 3) o da reciprocidade, no qual as relações estabelecidas entre grupos ou pessoas são levadas a cabo visando à manutenção do laço social (LAVILLE, 2004: 21-22). Segundo, ainda, este autor, através desses três princípios, a Economia pode ser decomposta em três pólos: 1) Economia Mercantil - a produção e distribuição são realizadas prioritariamente no mercado; 2) Economia nãoMercantil - a distribuição de bens e serviços se confia prioritariamente pela redistribuição organizada pelo Estado; 3) Economia não-M onetária corresponde à forma na qual a produção e distribuição são realizadas através da reciprocidade que, em alguns casos, pode assumir uma forma monetarizada (LAVILLE, 2004: 22). N esta perspectiva, a Economia solidária não seria uma formação econômica baseada nas solidariedades reciprocitárias e distributivas, em oposição a uma baseada no princípio de Mercado. A Economia Solidária seria, então, 
uma tentativa de articulação inédita entre economia mercantil, não-mercantil e não-monetária numa conjuntura que se presta a tal [...]. O desafio é de acumular as vantagens da economia monetária, fonte de liberdade individual pelo mercado e fator de igualdade pela redistribuição, com aquelas da economia nãomonetária que contextualiza as trocas, retirando-as do anonimato. (FRANÇA FILH O; LAVILLE, 2004: 107)

Assim, a Economia Solidária, na perspectiva de Laville, seria muito mais "[... ] um híbrido formado por atividades recíprocas desenvolvidas por voluntários, atividades de mercado por profissionais, e atividades financiadas por subsídios estatais" (SIN GER, 2004: 7), do que uma forma de superação e ruptura com a Economia Capitalista.

Em contraposição, Euclides André Mance e Paul Singer concebem a Economia Solidária como uma forma antagônica de organização da Economia em relação à capitalista. Para $\mathrm{M}$ ance, o potencial das iniciativas de Economia Solidária em se constituírem numa alternativa ao capitalismo está ligado à noção de colaboração solidária. Esta consiste na:

estratégia para organização de uma sociedade pós-capitalista, baseada na implantação de redes que conectam unidades de produção e de consumo, em um movimento recíproco de realimentação, permitindo a geração de emprego e renda, o fortalecimento da economia e do poder locais, bem como uma transformação cultural das sociedades em que se implanta, com a afirmação de uma ética e de uma visão de mundo antagônicas não apenas ao neoliberalismo mas ao próprio capitalismo. (M AN CE, 1999: 203)

Esse processo de mudança defendido por Mance é denominado por ele de Revolução das Redes. Esta seria um movimento no sentido de superação da organização econômica e social capitalista cuja força motriz é 
uma nova maneira ideologicamente orientada de consumir que, por sua vez, organizaria uma nova forma de produção econômica. Assim, através das relações entre consumidores e produtores surgiriam redes que visariam à satisfação das necessidades e à geração de trabalho e renda dos seus participantes. É a partir deste "circulo virtuoso" de consumo e produção que surge, junto à sociedade capitalista, uma nova forma de organização social e econômica que, à medida que aumentam suas dimensões, substituiria o capitalismo. Todo este movimento tem como ponto de partida o consumo solidário que "ocorre quando a seleção do que consumimos é feita não apenas considerando o nosso bem-viver pessoal, mas também o bem-viver coletivo, uma vez que é no consumo que a produção se completa e este tem impacto sobre [... ] a sociedade em geral" (MANCE, 1999: 13).

Para Paul Singer, o potencial transformador da Economia Solidária seguiria uma outra dinâmica. Segundo este autor, o cooperativismo autogestionário representaria a forma mais radical de organização da atividade econômica através de princípios anticapitalistas. Em outros termos, as experiências cooperativas mostram “[...] que os trabalhadores têm capacidade de organizar atividades econômicas segundo princípios próprios, socialistas [...]" (SIN GER, 1999: 113). Assim, a cooperativa autogestionária assume uma centralidade na construção de uma alternativa ao capitalismo, a Economia Solidária. E essa centralidade se deve ao fato de que a cooperativa autogerida...

realiza em alto grau todas as condições para a desalienação do trabalho e, portanto, para a realização do socialismo [...]. Ela é gerida pelos trabalhadores, as relações de trabalho são democráticas, ela traduz na prática o lema: "de cada um segundo suas possibilidades, a cada um segundo suas necessidades". (SIN GER, 1999: 128) 
Assim, devido as suas características (propriedade coletiva, gestão democrática e sistemas mais ou menos igualitários de distribuição dos ganhos e perdas econômicas), as cooperativas autogeridas reapresentariam a unidade básica, mas não suficiente, pela qual se pode constituir um modo de produção alternativo ao capitalista - o modo de produção solidário. Em suma, na perspectiva de Singer, a Economia Solidária é entendida como:

outro modo de produção, cujosprincípios básicossão a propriedade coletiva ou associada do capital e o direito à liberdade individual. A aplicação dessesprincípiosune todos os que produzem numa única classe de trabalhadoresque são possuidores de capital por igual em cada cooperativa ou sociedade econômica. $O$ resultado natural é a solidariedade e a igualdade, cuja reprodução, no entanto, exige mecanismos estatais de redistribuição solidária da renda. (SIN GER, 2002a: 10).

Nosso objetivo aqui não é entrar no debate de qual dessas perspectivas teóricas melhor define e teoriza sobre as iniciativas e organizações às quais o termo Economia Solidária se refere; e, sim, destacar que é somente na perspectiva de Paul Singer que o modelo de cooperativismo autogestionário adquire uma centralidade como, primeiro, uma forma de organização econômica par excellence daquilo que, na visão do autor, poderíamos entender por Economia Solidária e, segundo, porque seria através de experiências autogestionárias que homens e mulheres encontrariam as condições necessárias para incorporar e pôr em consecução práticas orientadas por valores ideológicos como a solidariedade, participação, igualdade e cooperação. Portanto, podemos dizer que Paul Singer estabelece uma equivalência entre valores ideológicos da Economia Solidária e autogestão que, ao seu turno, fundamenta a relação teórica de codeterminação entre o modelo autogestionário e os valores ideológicos dos trabalhadores. $\mathrm{N}$ a seção seguinte, iremos aprofundar em que consiste essa relação de co-determinação presente na perspectiva de Paul Singer. 


\section{Cooperativismo Autogestionário}

Como foi destacado, as iniciativas de Economia Solidária nasceram no contexto de crise do fordismo-taylorismo e do avanço de políticas neoliberais. Todavia, no caso brasileiro, temos ainda o processo de redemocratização criando condições institucionais mais favoráveis à livreassociação e, ainda, maior liberdade para entidades da sociedade civil que, mesmo durante o Regime Militar (1964-1988), atuavam na promoção da organização econômica associativa dos setores mais pobres da população - esse é o caso, por exemplo, dos Projetos Alternativos Comunitários (PACs) promovidos pela Cáritas, entidade ligada à Conferência N acional dos Bispos do Brasil (CNBB). Ademais, a abertura econômica do País promovida pelo governo Collor no início da década de 1990, que provocou o processo de reestruturação produtiva, aumento das taxas de desemprego e o fechamento de empresas que não resistiram ao aumento da competição. Em decorrência destes fatores sociais, políticos e econômicos surgem, então, iniciativas econômicas dos mais diferentes tipos: empresas autogeridas, nascidas quando os trabalhadores assumem, sob a forma de cooperativa, a massa falida da empresa privada na qual trabalhavam; bancos populares ou sistemas de microfinanças que atuam fomentando e organizando o comércio local de comunidades de baixa renda; associações de pequenos produtores agrícolas; os diferentes tipos de pequenos empreendimentos e de trabalho autônomo que atuam na chamada economia informal (comerciantes ambulantes, "carrocinhas" de cachorro-quente, etc.); cooperativas de trabalho, resultantes dos processos de flexibilização nos quais, por exemplo, trabalhadores do setor de uma empresa são demitidos e "incentivados" a formarem uma cooperativa para ser subcontratada pela mesma empresa que os demitiu antes ${ }^{3}$ entre outros.

3 Lima (2002) realiza uma ótima pesquisa sobre esse tipo de cooperativa que surge como produto de processos de flexibilização. 
Dada essa diversidade, autores como Paul Singer se vêem obrigados a melhor definir e diferenciar esses diferentes tipos de empreendimentos ${ }^{4}$. N esse sentido, para Singer é o modelo de autogestão que define se um empreendimento é ou não de Economia Solidária, pois, para este autor (2002a: 16-23; 2002b: 86), tal modelo seria a forma concreta de realização dos princípios de solidariedade, igualdade, participação e cooperação nas atividades econômicas: "Pegando a palavra 'autogestionária' como síntese, é exatamente isso: igualdade e democracia [...]" (SIN GER, 2000b: 149). É a autogestão, portanto, que distingue os empreendimentos solidários dos demais.

Basicamente, as características da organização autogestionária são as seguintes: posse coletiva dos meios pelos quais os indivíduos exercem a atividade econômica (produção, poupança, serviços, etc.); gestão democrática e igualitária do empreendimento através do princípio "um membro igual a um voto" e, sendo, assim, o órgão máximo de decisões é a assembléia geral; divisão dos ganhos e perdas financeiras da empresa de forma igualitária ou por critérios acordados pelo coletivo, e recusa ao assalariamento permanente. É devido a estas características que o modelo autogestionário, segundo Singer, ofereceria as condições para que os trabalhadores incorporassem valores ideológicos diferentese até mesmo opostos daqueles presentes nas relações sociais e econômicas capitalistas:

Tanto a autogestão como a heterogestão apresentam dificuldades e vantagens, mas seria vão tentar comparálas para descobrir qual delas é a melhor. São duas modalidades diferentes de gestão econômica que servem a fins diferentes. A heterogestão parece ser eficiente em tornar empresas capitalistas competitivas e lucrativas, que é o que seus donos almejam. A autogestão promete ser eficiente em tornar empresas solidárias, além de

4 Em Karychete, Lara e Costa (2000) podemos verificar alguns dos diferentes esforços de definição e diferenciação dessas iniciativas econômicas. 
economicamente produtivas, centros de interação democráticos e igualitários (em termos), que é o que seus sócios precisam. (SIN GER, 2002a: 23).

Assim, a autogestão, nesta perspectiva, não é apenas uma modalidade técnica de organização e gestão. Ela seria a soma de práticas e saberes orientados por princípios e valores (solidariedade, igualdade, cooperação, autonomia, participação, democracia, viabilidade econômica, etc.). Nesta direção, afirmamos que Paul Singer estabelece uma relação de co-determinação entre autogestão e os valores ideológicos dos trabal hadores; pois, na perspectiva desse autor, as práticas de trabalho autogerido só poderiam ser "verdadeiramente" levadas a cabo por pessoas que incorporassem e orientassem sua conduta através de valores como a igualdade, cooperação, solidariedade e participação. É em razão desta vinculação entre valoresideológicos de Economia Solidária e autogestão que, para Singer (2000a, 2000b), a experiência de trabalho autogerido possuiria um potencial educativo, isto é, a prática do modelo de autogestão permitiria educar e transformar o comportamento das pessoas através da incorporação de valores ideológicos de Economia Solidária.

A autogestão tem como mérito principal não a eficiência econômica (necessária em si), mas o desenvolvimento humano que proporciona aos praticantes. Participar das discussões e de decisões do coletivo, ao qual se está associado, educa e conscientiza, tornando a pessoa mais realizada, autoconfiante e segura. (SIN GER, 2002a: 21)

Assim, a participação num empreendimento autogerido não seria apenas uma questão de interesse econômico, mas envolveria uma opção e educação político-ideológica do trabalhador "[... contra os valores dominantes da competição individual e da primazia do capital sobre o trabaIho" (SIN GER, 2000a: 21-22). Portanto, para Paul Singer, a constituição de 
empreendimentos autogeridos não representaria apenas uma alternativa encontrada pelos trabalhadores ao assalariamento (ou à falta dele) e à pobreza, mas seria, também, o estabelecimento das condições e do conjunto de práticas capazes de transformar a consciência e o comportamento dos seus praticantes.

É preciso destacar que, para Singer, esta "educação" para e através da autogestão não acontece de forma automática, isto é, o autor (SIN GER, 1999; 2000a, 2000b) menciona que pode acontecer que os trabalhadores se insiram em organizações autogestionárias, a partir de valores que não aqueles que, a priori, são os da autogestão e, por conseguinte, da Economia Solidária. Todavia, esses outros valores não são vistos como uma produção dos sujeitos para prática da autogestão e, sim, como algo advindo e incorporado pelos trabalhadores através da cultura do regime de assalariamento e das relações sociais capitalistas e, portanto, são formas de comportamento que poderiam "corromper" a integridade do modelo de autogestão: "O perigo da degeneração da prática autogestionária vem, em grande parte, da insuficiente formação democrática dos sócios" (SIN GER, 2002a: 21). Portanto, outros valores incorporados pelos trabalhadores que não os de Economia Solidária e que poderiam conformar outras formas de inserção e prática da autogestão são vistos como influências do sistema capitalista, capazes, em alguns casos, de corromper a "verdadeira" realização do modelo de autogestão. Enfim, no nosso entender, essa perspectiva de Singer sobre a relação entre valores ideológicos dos trabalhadores e a consecução da autogestão é criticável, pois excluí a possibilidade de formas de inserção e participação no empreendimento autogestionário através da incorporação de valores diferentes daqueles de Economia Solidária.

Por fim, é digno de nota, que o modelo autogestionário pode ser realizado nos diversos tipos de empreendimentos solidários - banco popular, associações, sistemas de trocas-locais, etc. Todavia, Singer coloca a 
cooperativa como a forma por excelência de organização do modelo autogestionário. De acordo com esse autor, a cooperativa de produção é o "protótipo da empresa solidária". Ela detém um papel central na organização da Economia Solidária como setor econômico definitivo. A centralidade da autogestão e do cooperativismo, na perspectiva de Paul Singer direcionou nossa escolha em tomar como objetos empíricos de análise duas cooperativas autogestionárias, para que nossas críticas em relação a este autor fossem construídas a partir do mesmo objeto de estudo.

\section{Valores Ideológicos}

Pensamos que, se adotássemos a perspectiva de Singer, ela nos levaria a entender que os valores ideológicos são produtos de condições e práticas objetivas que se encerram no modelo de autogestão. Assim, existiriam os "verdadeiros" valores da prática autogestionária cabendo ao praticante incorporá-los ou não. Em contraposição, defendemos a idéia de que os valores ideológicos não residem no modelo autogerido, mas nos trabalhadores e, por conseguinte, que não existem verdadeiros ou falsos valores e, sim, valores que denotam formas de inserção e participação no empreendimento autogerido. Enfim, para superar esse modelo "normativo" de Singer na compreensão dos valores ideológicos, adotamos nesta pesquisa o conceito de ideologia de Martin Seliger (1976). Esta última é definida como um sistema de pensamento que permite aos sujeitos justificar e conduzir uma ação social organizada (no caso da nossa pesquisa, a cooperativa autogerida):

All ideologies are [...] neither paradigms of logical argumentation nor entirely illogical structures. They are 'systems', inasmuch as certain values, factual assessments and commitments to ends and means are deliberately fused in order to ensure that through concerted action certain forms of social organization 
will be defended, abolished, reconstructed or modified. (SELIGER, 1976: 99)

Portanto, ideologia denota o processo pelo qual os agentes "organizam" determinado conjunto de crenças, valores e princípios, de modo tal, que Ihes permita, através da ação social organizada, perseguir objetivos políticos, sociais e/ou econômicos. Isto faz com que as ideologias sejam misturas de enunciados descritivos e analíticos, de um lado, e prescrições morais e técnicas, do outro. E é exatamente essa combinação em um sistema relativamente coerente de pensamento e argumentação, que confere à ideologia o poder de guiar e justificar uma ação.

No entanto, esse processo de organização de um conjunto de crenças nunca é definitivo, pois a necessidade de consecução da ação prática (necessidade esta, reforçando característica da ideologia), em algum momento, compromete os princípios e valores mais gerais de uma ideologia. Isto é, quando a ideologia é formada para exercer sua função, guiar a ação social, ela é confiada para estruturar e/ou justificar medidas práticas específicas, sendo que, neste processo, a centralidade e "pureza" de alguns princípiose valores provavelmente tornar-se-ão ameaçados pela necessidade de ação. Essa tensão entre ideologia e ação faz com que, segundo Seliger (1976), a ideologia se bifurque em duas dimensões interativas: 1) dimensão fundamental - nível no qual os valores gerais de uma ideologia são mantidos, reordenados e/ou modificados; 2) dimensão operativa - nível mais prático no qual as ações empreendidas pelos atores são defendidas. Sendo assim, muitas vezes, uma mesma formação ideológica abriga diferentes processos de acordos, ajustes e trocas entre os elementos mais fundamentais de uma ideologia e o seu conjunto de prescrições de ordem mais prática e concreta, sendo que esse processo de acordo é realizado pelos próprios indivíduos.

Deste modo, com base em Seliger (1976), entendemos por ideologia uma forma de pensamento e argumentação que serve para conduzir e justificar a ação social organizada e, derivando dessa definição, pode-se 
compreender que valores ideológicos são elementos que compõem a dimensão fundamental dessa forma de pensamento e argumentação.

Sendo a ideologia um sistema de pensamento que se estrutura através da articulação de duas dimensões, a saber, a fundamental na qual residem os valores mais gerais, e a operativa, formada por prescrições práticas que são justificadas pelo nível fundamental; podemos, então, identificar os valores ideológicos dos trabalhadores, analisando as diferentes formas pelas quais eles falam a respeito das práticas que realizam na consecução do modelo de autogestão (dimensão operativa da ideologia). Através desta análise, podemos inferir os valores incorporados pelos trabalhadores, em razão da relação entre dimensão operacional e fundamental.

Assim, a definição de ideologia de Seliger, nos permite compreender a incorporação de valores ideológicos como um processo realizado pelos indivíduos, visando justificar determinadas práticas numa ação social organizada. Todavia, a perspectiva de Seliger não nos permite entender por que uma mesma ação social pode ser justificada através da incorporação de valores diferentes. Em poucas palavras, como explicar a heterogeneidade ideológica entre participantes de uma mesma ação organizada. Neste sentido, os estudos sociológicos e de Psicologia social dos valores de trabalho nos oferecem elementos importantes para entendermos a heterogeneidade ideológica ${ }^{5}$.

Entre o final da década de 1970 e início da de 1980, estes estudos se ocupavam em testar duas hipóteses gerais sobre as relações entre trabalho e valores: 1) hipótese da socialização ocupacional - afirma que as experiências ocupacionais influenciam na formação da personalidade dos sujeitos e, mais especificamente, nos valores que os orientam; 2) hipótese da seleção ocupacional - propõe que as pessoas escolhem a sua ocupação, de acordo com uma base psicológica (incluindo aí os valores), anteriormente

5 Para uma revisão completa dos estudos nessa área, ver Hitlin e Piliavin, 2004. 
formada na infância e na adolescência (MORTIMER e LORENCE, 1979: 1361-1362). 0 que os estudos deste período demonstraram foi que, quando consideramosa relação entre trabalho e valores através de dados longitudinais, tanto a hipótese da socialização como a da seleção são verdadeiras. Em outros termos, "[... job conditions actually do affect personality, and also that personality affects job conditions" (KO H N e SCH O O LER, 1982: 1281). O s resultados desses estudos, de certo modo, corroboram com a perspectiva de Paul Singer sobre a relação entre trabalho autogestionário e a incorporação de valores de Economia Solidária; pois ambas as perspectivas sustentam que valores e experiências de trabalho têm uma relação de co-determinação, ou seja, que a realização ou escolha de um trabalho está ligada a um conjunto de valores anteriormente existente (hipótese da seleção ocupacional) e que a experiência desse trabalho pode mudar ou consolidar esses valores (hipótese da socialização ocupacional). Contudo, tendo em vista essa perspectiva, como explicar que, numa mesma experiência de trabalho (por exemplo, o autogestionário), exista a incorporação de diferentes valores? Para responder a essa pergunta é preciso levar em consideração outros resultados de pesquisas na área dos estudos sociológicos e da Psicologia social sobre valores ligados ao trabalho.

As pesquisas desenvolvidas na década de 1980 até o presente momento buscam explicar a formação e diferenças de valores de trabalho entre as pessoas, através de um modelo analítico mais amplo do que aquele anterior. Por exemplo, Lindsay e Knox (1984) destacam que variáveis como gênero, status socioeconômico da família e raça, estão relacionados aos valores dos indivíduos. Além disso, esses autores propõem que também o nível educacional interfere tanto no processo de seleção como no de socialização no trabalho. Também Halaby (2003) destaca o papel de variáveis como status da família de origem, escolaridade e gênero para entendermosa existência e mudança nos valores ligados ao trabalho. Johnson (2002) 
vai enfatizar a influência destas variáveis e mais o tipo de comunidade de origem (rural ou urbana), religião e raça, para explicar diferentes padrões de mudanças nos valores de trabalho. Deste modo, essas pesquisas apontam que a incorporação de diferentes valores relacionados a uma mesma experiência de trabalho reside na "variabilidade" dos indivíduos - variabilidade esta definida em termos de gênero, raça, status socioeconômico, escolaridade, etc. Enfim, através da definição de ideologia de Seliger (1976) e dos estudos sociológicos e de Psicologia Social sobre valores do trabalho, podemos elaborar uma perspectiva sobre a relação entre autogestão e valores ideológicos dos trabalhadores, que compreenda a incorporação de valores como um processo realizado pelo indivíduo, sendo justamente a "variabilidade" deste último o elemento pelo qual podemos explicar a heterogeneidade ideológica numa mesma experiência de trabalho.

\section{Os Perfis Ideológicos}

Através da análise de conteúdo de 42 entrevistas com participantes de duas cooperativas de produção autogeridas, identificamos uma heterogeneidade de valores ideológicos que os trabalhadores incorporaram para justificar as práticas do modelo de autogestão. M ostraremos esta heterogeneidade através da definição de três perfis ideológicos dos trabaIhadores, mas antes faremos fazer uma breve descrição das cooperativas estudadas e do modo como operacionalizamos nosso processo de análise.

As duas cooperativas autogeridas de produção atuam no ramo da metalurgia e se localizam, respectivamente, nos municípios de Porto Alegre e Canoas no Estado do Rio Grande do Sul (Brasil). 0 empreendimento localizado em Porto Alegre foi fundado em dezembro de 2002 a partir da falência de uma empresa privada. Inicialmente a cooperativa foi constituída por 25 ex-funcionários da antiga empresa, entretanto, alguns destes 
saíram do empreendimento por diversos motivos - financeiro, não adaptação ao modelo de cooperativa, saúde, etc. - e outros retornaram à empresa, à medida que o processo produtivo foi se desenvolvendo. $\mathrm{Na}$ época do trabalho de campo, a cooperativa contava com 20 sócios-trabalhadores, muitos dos quais, devido ao número reduzido de pessoas e ao pequeno porte da empresa, atuavam tanto na parte administrativa quanto na parte produtiva do empreendimento. Em 2004, foram feitas oito entrevistas com cooperativados que fazem parte da administração e/ou produção. Já a cooperativa de Canoas foi fundada no início de 2001, também a partir da falência de uma empresa privada. Um total de 20 trabalhadores ocupou de maneira permanente a fábrica falida e ali permanecem até que se consolidasse a formação da cooperativa. Havia uma encomenda sendo feita durante este período, que foi entregue e paga pelo cliente quando da sua conclusão. Foi com este capital que se iniciou o novo processo de produção. À medida que a cooperativa se consolidava, outros antigos empregados foram voltando e se integrando ao empreendimento. A cooperativa, na época da realização do estudo, contava com 143 sócios-trabalhadores e foram realizadas 34 entrevistas em 2003.

Sendo a ideologia uma forma de pensamento e argumentação que serve para conduzir e justificar a ação social organizada, procuramos apreender nas entrevistas o modo como os sujeitos justificam e percebem a experiência e as práticas de autogestão. N esta perspectiva, estabelecemos algumas dimensões e indicadores que pensamos serem característicos da experiência de autogestão, sendo estas as dimensões que orientaram a organização dos processos de entrevistas e de análise de conteúdo destas, sendo elas: 1) propriedade coletiva: trata-se da avaliação que o entrevistado faz sobre o sistema de remuneração da cooperativa e o tipo de sentimento de posse, ou não, que ele apresenta em relação ao empreendimento; 2) processos de participação, são as falas nas quais os trabalhado- 
res expressam o que acham dos processos decisórios no âmbito da gestão da cooperativa, tais como assembléias gerais, conselhos e comitês, exposição de informações sobre a situação financeira da empresa, etc.; 3) relação entre pares, é o modo como o cooperativado enxerga seu relacionamento com os pares, o caráter da união entre eles; 4) objetivos, expectativas e resultados, que eles visam e avaliam terem alcançado por meio do empreendimento autogerido. Através do item 4, podemos inferir a orientação que os trabalhadores de determinado perfil ideológico têm na ação social organizada (na cooperativa autogerida). Foi justamente a partir do modo como os trabalhadores justificam e debatem sobre essas dimensões da autogestão, assim como a orientação que eles têm na ação social organizada, que foi possível identificar quais valores ideológicos os trabalhadores incorporaram. 0 quadro seguinte ilustra quais são esses valores e os perfis ideológicos que eles conformam:

Q uadro - Princípios ideológicos e orientação na ação social de cada perfil ideológico.

\begin{tabular}{|c|c|c|c|}
\hline & Perfil de Solidariedade & Perfil de Assalariamento & $\begin{array}{l}\text { Perfil de Instrumentalização } \\
\text { Capitalista }\end{array}$ \\
\hline O rientação na ação social & $\begin{array}{l}\text { - Consolidação do mo- } \\
\text { delo de cooperativismo } \\
\text { autogestionário. }\end{array}$ & $\begin{array}{l}\text { - Garantir para si uma certa } \\
\text { continuidade de lógica e ati- } \\
\text { tude entre o modelo de } \\
\text { assalariamento e o de } \\
\text { cooperativismo. }\end{array}$ & $\begin{array}{l}\text { - Consolidação econômica do } \\
\text { empreendimento através da in- } \\
\text { serção pura e simples no mer- } \\
\text { cado. }\end{array}$ \\
\hline Propriedade coletiva & - Igualdade & - Individualismo & - M eritocracia \\
\hline Processos de participação & $\begin{array}{l}\text { - Participação } \\
\text { - Igualdade } \\
\text { - União }\end{array}$ & $\begin{array}{l}\text { - Individualismo } \\
\text { - Produtividade }\end{array}$ & - Controle \\
\hline Relação entre os pares & - Solidariedade & - Coleguismo & - Cooperação \\
\hline
\end{tabular}


O perfil ideológico de solidariedade, como o próprio nome já deixa evidente, é o perfil ideológico de Economia Solidária, isto é, trata-se de trabalhadoresque expressam valores e princípios como solidariedade, igualdade, participação e democracia. Nesse sentido, a orientação na ação social organizada dos trabalhadores deste perfil é, principalmente, a consolidação do modelo autogestionário. Isso se expressa quando os trabalhadores de perfil solidário falam da preocupação de todos os sócios da cooperativa em "mudarem seu comportamento de empregado, para cooperativado", isto é, não basta apenas que cada um exerça a sua função no processo produtivo (modelo de assalariamento), mas que cada um participe da gestão da cooperativa e assim, fazer com que cada cooperativado se reconheça como integrante de um projeto coletivo.

É com relação ao caráter coletivo e autogestionário do empreendimento, que os trabalhadores de perfil solidário justificam a propriedade coletiva da cooperativa, através do valor da igualdade. Este princípio se manifesta quando os trabalhadores de perfil ideológico de solidariedade justificam que, sendo a cooperativa um empreendimento coletivo, todos têm o mesmo direito e dever de participar da sua gestão, do seu desenvolvimento e dos seus resultados. Além disso, o princípio de igualdade justifica o posicionamento desses trabalhadores sobre o sistema de remunerações que eles pensam ser mais justo. Na cooperativa de Porto Alegre, os trabalhadores relataram que, no processo de fundação do empreendimento, foram discutidas duas propostas de sistemas de remunerações mensais para os sócios: o primeiro se estruturava em três faixas de remunerações diferenciadas entre si, dadas a partir de critérios de qualificação do cooperado; no segundo sistema (que foi o escolhido), o "lucro" mensal da cooperativa é dividido igualmente entre todos os sócios. 0 posicionamento dos trabalhadores de perfil ideológico de solidariedade era de defesa do sistema de divisão igualitária dos ganhos mensais, pois, afinal, a proprieda- 
de da cooperativa e a gestão desta são coletivas. Assim, a igualdade serve para justificar, tanto o direito e o dever da participação e o comprometimento de todos com a cooperativa, quanto para justificar um sistema de remuneração igualitário.

No que se refere aos processos de participação, os trabalhadores de perfil de solidariedade expressam, nas suas falas, os princípios de igualdade, união e participação. Por exemplo, as assembléias gerais, para eles, são um espaço de deliberação, debates e busca por soluções coletivas para os problemas da cooperativa; não é um espaço de conflito, cobranças e controle de cada um sobre o outro (concepção dos trabalhadores de perfil de instrumentalização capitalista). A assembléia é justificada, então, por ser um espaço do qual todos podem igualmente participar e onde a união e a solidariedade do grupo são reforçadas.

O princípio de solidariedade, obviamente, está bastante presente nas falas dos trabalhadores de perfil ideológico de solidariedade. É preciso destacar que não estamos aqui partindo de uma noção teórica de solidariedade (neste sentido, ver SINGER, 2002a: 7-11; M ANCE, 1999: 17-19; LISBO A, 2003: 242-250), mas, sim, de uma noção elaborada a partir das falas dos trabalhadores. Desta forma, a noção de solidariedade é diferente da simples cooperação, isto é, solidariedade remete à idéia de um coletivo e não à simples soma de esforços individuais coordenados para um objetivo comum (cooperação). Neste sentido, nos trabalhadores deste perfil ideológico, o princípio de solidariedade serve para justificar uma forma de relação entre os pares, que leve em consideração o interesse do grupo e, assim, reconhecer-se como integrante de um projeto comum. Portanto, 0 princípio de solidariedade, neste perfil ideológico de trabalhadores, fundamenta a percepção e a justificação de como é (deve ser) a relação entre os membros da Cooperativa, fazendo com que todos tenham um maior envolvimento e uma maior participação no processo de gestão e produ- 
ção. Enfim, a solidariedade remete à idéia de um comprometimento com o coletivo.

Concluindo, percebe-se que o perfil ideológico de solidariedade expressa os valores e princípios fundamentais de Economia Solidária, a saber, igualdade, participação, solidariedade e união. A inter-relação entre esses princípios, de certo modo, conforma uma forma de pensamento e argumentação sobre a experiência de autogestão (uma orientação na ação social organizada) que visa principalmente a consolidação do modelo de cooperativismo autogestionário de Economia Solidária.

A caracterização através da palavra "assalariamento" para o segundo perfil ideológico encontrado é em função de que um determinado conjunto de trabalhadores expressa valores e princípios, como veremos em seguida, que constituem uma atitude e discurso que visa propiciar para si uma certa continuidade ou, até mesmo, negar a diferença entre o contexto de trabalho assalariado e o autogerido. Assalariamento porque a Cooperativa, para os trabalhadores deste perfil ideológico, é um trabalho como qualquer outro, sendo que a "opção" por trabalhar na Cooperativa se faz em função da perda e da falta de perspectiva de encontrar um emprego. Em suma, a orientação, na ação social organizada do perfil de assalariamento é garantir uma espécie de continuidade para si entre a lógica do modelo de trabalho assalariado e a do modelo de cooperativismo autogestionário.

Esta orientação dos trabalhadores de perfil de assalariamento faz com que eles neguem a propriedade coletiva, isto é, nas suas falas, eles não expressam um sentimento de posse em relação à Cooperativa. Notamos que, negando o aspecto da propriedade coletiva, os trabalhadores deste perfil ideológico, de certo modo, conseguem perceber a cooperativa tal como uma empresa e, neste sentido, ser cooperativado passa ser um "empregado da cooperativa". A partir desse entendimento sobre "o que é a 
cooperativa", eles expressam, nas suas falas, o princípio do individualismo. Este último, não só favorece a recusa do caráter coletivo do empreendimento, como também possibilita a baixa participação desses trabalhadores na gestão da cooperativa. Entretanto, o reduzido envolvimento nos processos de participação é compensado por outro princípio, o da produtividade no trabalho, isto é, não a produtividade no sentido da busca de ganhos econômicos e, sim, de fazer o seu trabalho direito. Através desse princípio, o cooperativado pertencente ao perfil ideológico de assalariamento valoriza a atividade laboral propriamente dita (" $O$ negócio é baixar a cabeça e trabalhar aqui", como disse um trabalhador), em detrimento do envolvimento nos processos de participação, ou seja, os processos participativos são vistos como "perda de tempo", tempo este que deveria ser utilizado para trabalhar. Em suma, a negação da propriedade coletiva da cooperativa manifesta o princípio do individualismo que, por sua vez, faz com que o trabalhador de perfil de assalariamento adote um distanciamento em relação aos processos de participação e, assim, essa postura de não envolvimento é justificada através da valorização da atividade laboral em si, ou seja, através do valor da produtividade no trabalho.

Outro princípio expresso nas falas dos trabalhadores de perfil de assalariamento é o coleguismo. Este último é diferente da noção de solidariedade e cooperação. 0 coleguismo remete a um tipo de união entre os cooperados, sem envolver a idéia de coletivo (presente na solidariedade) e sem a questão do direcionamento de esforços e talentos individuais para a busca de um objetivo comum (cooperação). O coleguismo são apenas relações de simpatia e antipatia. Assim, o princípio de coleguismo justifica e conduz a um tipo de relação entre os pares, mais ligada à amizade do que a um elo a partir de uma identificação com um projeto comum (no máximo o reconhecimento de que estão todos na mesma situação). Disso resulta que esses trabalhadores percebem que sua relação com os pares é 
basicamente a mesma, na medida em que eles continuam sendo amigos de quem eram antes da falência da empresa privada e sua transformação em cooperativa.

Podemos, deste modo, identificar três princípios neste grupo de trabalhadores que formam o perfil ideológico de assalariamento, a saber, individualismo, produtividade e coleguismo. Esses princípios justificam e conduzem uma orientação na ação social organizada que busca, fundamentalmente, uma certa continuidade para si, no sentido de uma lógica e atitude no trabalho, entre empresa privada e cooperativa.

Por último, os trabalhadores de perfil ideológico de instrumentalização capitalista, como veremos, não só expressam, nas suas falas, valores diferentes dos de Economia Solidária como, também, opostos a esta última. Para os trabalhadores deste perfil, ao contrário dos de perfil de solidariedade, a orientação na ação social organizada não é a consolidação do modelo de autogestão e, sim, garantir o desenvolvimento econômico da cooperativa, trazendo resultados financeiros crescentes para os cooperados, dentro de uma lógica produtiva e competitiva. Assim, pode-se dizer que esse perfil ideológico concebe um modelo de cooperativismo alternativo ao de Economia Solidária, voltado para a competitividade e a inserção pura e simples no mercado capitalista, tal como qualquer empresa privada. 0 desenvolvimento da autogestão, em vez de se tornar uma meta a ser alcançada, tal como é vista no perfil solidário, é instrumentalizado como meio para se atingirem resultados financeiros. Isso se verifica quando os trabalhadores de perfil de instrumentalização capitalista destacam a importância de se fazerem mudanças e aperfeiçoamentos técnicos, financeiros e administrativos para assegurar a competitividade e o crescimento econômico do empreendimento. Em outras palavras, não é o modelo e as práticas de autogestão em si que precisam ser aperfeiçoadas, mas fatores financeiros e relativos à organização do processo produtivo e, também, 
não no sentido de consolidar um projeto coletivo, mas como possibilidade de inserção competitiva no mercado. Portanto, os valores e princípios desses trabalhadores estão articulados, no sentido de justificar e conduzir a experiência de cooperativismo autogestionário como uma forma de associação com fins essencialmente econômicos.

O s trabalhadores de perfil ideológico de instrumentalização capitalista, no que se refere à propriedade coletiva, expressam o princípio da meritocracia, isto é, ser sócio do empreendimento só se justifica a partir do esforço e comprometimento pessoal para com o crescimento econômico e financeiro da Cooperativa. Nesta direção, para os trabalhadores deste perfil ideológico, a retribuição não se dá em relação ao esforço de cada um, mas aos resultados concretos deste esforço, sendo que aquele que se esforça, masnão produz suficientemente, não merece retribuição. 0 princípio da meritocracia se manifesta de maneira mais evidente quando os trabalhadores desse perfil falam da questão, comentada anteriormente, sobre o sistema de remunerações mensais. Para os trabalhadores de perfil de instrumentalização capitalista, o sistema igualitário de remuneração é injusto; para eles a retribuição deveria ser proporcional à produtividade, qualificação e posição que cada trabalhador ocupa na Cooperativa, isto é, a remuneração deveria ser proporcional a esses méritos individuais.

Q uanto aos processos de participação, ao contrário daqueles de perfil de solidariedade, para os trabalhadores de perfil de instrumentalização capitalista não é o princípio da participação e união que justifica os processos participativos como a assembléia geral e, sim, o controle. O s processos participativos são uma possibilidade de se ter controle da situação financeira e dos problemas na Cooperativa, isto é, por meio desse princípio os trabalhadores de perfil de instrumentalização capitalista justificam e percebem os processos de participação como espaços que servem, essencialmente, para controlar a situação financeira do empreendimento e, tam- 
bém, o cumprimento ou não das funções que cada um tem para garantir o bem-estar e o crescimento econômico da Cooperativa. Por isso, neste perfil ideológico, os processos de participação, antes de representarem uma forma de gestão coletiva do empreendimento (como o é para os trabalhadores de perfil de solidariedade), são mecanismos que visam a assegurar o controle de que todos os sócios estão comprometidos com a eficiência e progresso econômico e que ninguém está sendo ludibriado nos seus interesses pessoais pela sociedade e, também, que esta última não está sendo prejudicada por algum sócio.

No que se refere à relação entre os pares, ela é justificada e pensada a partir do princípio de cooperação, isto é, nos trabalhadores de perfil de instrumentalização capitalista, a relação é essencialmente aquela na qual cada um, a partir do esforço individual na sua função laboral, soma para o crescimento e o bom andamento econômico da Cooperativa, restringindo, assim, a ajuda mútua ao processo de produção e, por sua vez, instrumentalizando o caráter coletivo do empreendimento. Cooperação, então, não é no sentido de Economia Solidária, que a define como uma lógica social e econômica oposta à lógica competitiva capitalista. Neste perfil, a cooperação adquire um significado meramente instrumental, ou seja, como coordenação de capacidades e interesses individuais na busca de resultado econômico, o lucro.

Finalizando, vimos que a orientação do perfil ideológico de instrumentalização capitalista, na ação social organizada, é de consolidação e crescimento econômico-financeiro do empreendimento, a partir da concepção de um modelo de cooperativismo de cunho capitalista. Assim, a cooperativa é percebida e justificada através da coordenação de esforços individuais, na direção de um objetivo comum (ganho econômico). Deste modo, esse perfil ideológico nas suas falas expressa os seguintes princípios: meritocracia, controle e cooperação. 


\section{Considerações Finais}

Como vimos, a noção de Economia Solidária nasce de um esforço em compreender a lógica de determinadas iniciativas econômicas que surgem no último quartel do século XX. Autores como Paul Singer buscaram não somente compreender a lógica dessas iniciativas como, também, inspirados nelas, elaborar um projeto político-ideológico de transformação da sociedade. Em decorrência disso, Singer estabelece o que chamamos de relação de co-determinação entre, de um lado, valores ideológicos identificados com o projeto político-ideológico de Economia Solidária e, de outro, a consecução das práticas que conformam o modelo de organização dessas iniciativas, sendo que, para Singer, esse modelo seria o de autogestão. Deste modo, esta relação de co-determinação implica uma visão de que o modelo de autogestão proporcionaria a incorporação de valores de Economia Solidária (solidariedade, igualdade, participação, etc.) e, assim, tal modelo só poderia ser levado a cabo quando o comportamento dos trabalhadores estivesse orientado por esses valores. A perspectiva de Singer entende, então, que a condução das práticas de autogestão através da incorporação de outros valores ideológicos que não os de Economia Solidária, seria o resultado de uma espécie de "déficit pedagógico" do trabalhador, pois este não foi "educado" para "verdadeiramente" praticar a autogestão, que se faz através da incorporação de valores ideológicos como solidariedade, igualdade, participação, etc. Portanto, a perspectiva de co-determinação de Singer subentende que os valores ideológicos residem nas práticas que conformam 0 modelo de autogestão e que, por isso, para que os trabalhadores possam levar a cabo esse modelo, seria preciso que eles incorporassem os "verdadeiros" valores ideológicos da autogestão.

Pensamos ser criticável esta perspectiva sobre a relação entre autogestão e os valores ideológicos dos trabalhadores, porque ela não reconhece a possibilidade da inserção no, e de prática, do modelo 
autogestionário, através da incorporação de valores que não os de Economia Solidária. Em contraposição, nossa pesquisa empírica evidenciou uma heterogeneidade ideológica entre os trabalhadores de duas Cooperativas de produção, ou seja, identificamos formas de inserção e de consecução da experiência de trabalho autogerido através da incorporação ideológica de valores que não apenas os de Economia Solidária. Definimos esta heterogeneidade através da exposição de três perfis ideológicos de trabalhadores, na seção anterior deste artigo, quais sejam: 1) perfil de solidariedade, trabalhadores cuja orientação na ação social organizada é a consolidação do modelo de cooperativismo autogestionário de Economia Solidária. Assim, os trabalhadores de perfil ideológico solidário justificam e conduzem a experiência de autogestão através da incorporação de valores como igualdade, participação, solidariedade e união; 2) perfil de assalariamento, é o perfil no qual a orientação na ação social organizada é tentar garantir uma certa continuidade para si, principalmente no que se refere à atitude no trabalho, entre a experiência do modelo de assalariamento em empresa privada e o cooperativismo. O s valores incorporados por esses trabalhadores na autogestão são individualismo, produtividade e coleguismo; 3) perfil de instrumentalização capitalista, a orientação na ação social organizada deste grupo de trabalhadores é a consolidação e desenvolvimento econômico-financeiro da Cooperativa, tornando a autogestão apenas como um meio para inserção pura e simples no mercado. Tal perfil ideológico incorporou os valores e princípios da meritocracia, controle e cooperação. Entendemos que a existência destes perfis, isto é, da heterogeneidade ideológica no seio de cooperativas autogeridas não pode ser compreendida a partir da perspectiva de Singer, mesmo se, por exemplo, levando em consideração a visão deste autor, argumentasse que os diferentes perfis ideológicos denotam as dificuldades de os trabalhadores fazerem a transição do modelo de assalariamento para o autogerido. Os trabalhadores que 
não incorporaram os valores de Economia Solidária seriam, então, aqueles que não realizaram essa transição, ou seja, sofreriam de um "déficit pedagógico" para prática da autogestão. Este argumento seria verdadeiro se esta pesquisa tivesse apenas chegado a identificar dois perfis ideológicos 0 de solidariedade e o de assalariamento. Assim, o perfil de assalariamento seria aquele que efetivamente não faz a transição do modelo de empresa privada para o de cooperativa autogerida, fazendo com que o potencial educativo da autogestão não se realizasse nesse grupo. Todavia, através do perfil de instrumentalização capitalista, podemos vislumbrar mais nitidamente uma outra forma de participação no modelo autogestionário, que se estrutura através de valores ideológicos diferentes dos de Economia Solidária e que não pode ser explicado a partir do argumento de transição de regime de assalariamento para o autogestionário, porque os trabalhadores deste perfil participam tão ativamente dos processos de gestão (assembléias gerais, por exemplo) quanto os trabalhadores de perfil de solidariedade.

Deste modo, defendemos que, para compreender a existência destes perfis ideológicose, de modo geral, a relação entre os valores ideológicos dos trabalhadores e o trabalho autogerido, é preciso pensá-la através de um quadro teórico alternativo ao de co-determinação da perspectiva de Singer. Nesta direção, pensamos que o conceito de ideologia de M artin Seliger (1976) e os estudos sociológicos e de Psicologia Social sobre os valores de trabalho oferecem uma perspectiva que entende a relação entre a experiência de trabalho autogerido e os valores ideológicos dos trabalhadores como uma relação de autonomia relativa (e não de co-determinação), isto é, uma perspectiva que reconhece que o processo de formação de valores ideológicos depende tanto da experiência de trabalho autogerido como do sujeito social que expressa determinados valores. O s valores não residem apenas na experiência de trabalho autogerido per se, 
mas são produtos, tal como mostra Seliger, através das noções de dimensão fundamental e operativa da ideologia, de uma relação dialética entre o indivíduo e a experiência. Assim, nesta perspectiva, o papel do trabalhador no processo de incorporação de valores ideológicos deixa de ser compreendido como o de reproduzir e ser educado para agir conforme uma lógica já dada, para ser pensado como produtor dos valores que iriam conformar as lógicas de inserção e consecução do trabalho autogerido.

Se a idéia de uma relação de autonomia relativa permite pensarmos que quem realiza o processo de incorporação de valores ideológicos é o trabalhador, então, é a partir deste último que devemos buscar compreender a heterogeneidade ideológica. O s estudos sociológicos e de Psicologia Social dos valores de trabalho permitem romper com a perspectiva normativa implícita em Singer, que entende a incorporação de valores diferentes dos de Economia Solidária como resultado de um "déficit pedagógico" do trabalhador. Esses estudos apontam para o fato de que a incorporação de valores depende do que podemos chamar de filiação social do trabalhador, isto é, seu gênero, raça, status socioeconômico, estrutura familiar e formação educacional, entre outras variáveis que possam definir tal filiação. Portanto, é somente considerando a variabilidade desse sujeito social e o seu papel ativo no processo de incorporação de valores ideológicos, que pensamos ser possível entender a existência da heterogeneidade ideológica entre os participantes de uma mesma experiência de trabalho (no casso, a autogestionária).

Por fim, cabe destacar que a perspectiva aqui esboçada sobre a relação entre os valores dos trabalhadores e a experiência de trabalho autogerido como uma relação de autonomia relativa e que leva em consideração o papel criativo do trabalhador na produção dos valores que irão orientar a consecução deste tipo de experiência de trabalho leva-nos a lançar um outro olhar sobre o significado social e político mais amplo a 
respeito das iniciativas que o termo Economia Solidária pretende dar conta. De certo modo, contrapondo-nos a Singer, pensamos que o significado dessas iniciativas não seria propriamente 0 de que elas representariam "meios" capazes de operar uma transformação comportamental e moral nos trabalhadores, fazendo-os reproduzir princípios, valores e uma ordem moral que se pretende alternativa à capitalista; mas, no nosso entender, o significado de tais iniciativas seria muito mais o de oferecer aos trabalhadores as condições de ser em produtores dos valores e princípios pelos quais justificaram e conduziram seu trabalho. Talvez este seja o sentido propriamente dito da palavra autogestão, isto é, a de gerir seu trabalho conforme os seus próprios valores, sejam eles quais sejam.

\title{
The Values of Solidarity Economy
}

\begin{abstract}
According to Paul Singer's view on self-management, there is an implicit relationship of co-determination between the accomplishment of self-management practices and the assimilation of the ideological values of Solidarity Economy by the workers. This paper criticizes this relationship of co-determination following an empirical basis of 42 interviews with workers of two cooperatives. Thus, it was possible to identify a heterogeneity of ideological values, defined in three profiles: solidarity profile, employees profile, and capitalist instrumentation profile. The article argues that the existence of such profiles can not be explained by Singer's model of co-determination, and instead proposes an explanation based on sociological and sociopsychological studies on the values of work.
\end{abstract}

Keywords: Ideological values. Solidarity economy. Self-management and cooperatives. 


\section{Referências}

CORAGGIO, José Luis. Da economia dos setores populares à economia do trabaIho. In: KRAYCHETE, Gabriel; LARA, Francisco; COSTA, Beatriz (O rg.). Economia dos setores populares: entre a realidade e a utopia. Petrópolis: Vozes; Rio de Janeiro: Capina; Salvador: CESE; U CSAL, 2000. p. 91-141.

. Economia do trabalho. In: CATTANI, Antonio David (O rg.). A outra economia. Porto Alegre: Veraz, 2003. p. 88-96.

FAVREAU, Louis. Q u'est-ce que l'économie sociale? Synthèse introductive. O utaouais: Université du Q uébec en 0 utaouais; O bservatoire en économie sociale et en développement régional. 2005. Disponível em: < www.uqo.ca/observer/>.

FRAN ÇA FILHO, Genauto C. ; LAVILLE, Jean-Louis. A Economia Solidária: uma abordagem internacional. Porto Alegre: UFRGS, 2004.

GAIGER, Luiz I. G. Empreendimentos solidários: uma alternativa para a economia popular? In: _. (org.). Formas de combate e de resistência à pobreza. São Leopoldo: UN̄̄ISIN OS, 1996. pp.101-126.

HALABY, Charles N. Where job values come from: family and schooling background, cognitive ability, and gender. American Sociological Review, Washington, vol. 68, n² 2, p.251-278, 2003. Disponível em: http://www.periodicos.capes.gov.br/.

HITLIN, Steven ; PILIAVIN, Jane A. Values: reviving a dormant concept. Annual Review of Sociology, vol.30, Palo Alto, p.359-393, 2004. Disponível em: http:// www.periodicos.capes.gov.br.

ICAZA, Ana M ercedes Sarria; TIRIBA, Lia. Economia Popular. In: CATTAN I, Antonio David (O rg.). A outra economia. Porto Alegre: Veraz, 2003. p.101-109.

KO HN, M elvin L. ; SCHO O LER, Carmi. Job conditions and personality: a longitudinal assessment of their reciprocal effects. American Journal of Sociology, Chicago, vol. 87, n 6, p.1257-1286, 1982.

KRAYCHETE, Gabril. Economia dos setores populares: entre a realidade e a utopia. In: KRAYCHETE, Gabriel; LARA, Francisco; CO STA, Beatriz (O rg.). Economia dos setores populares: entre a realidade e a utopia. Petrópolis: Vozes; Rio de Janeiro: Capina; Salvador: CESE; U CSAL, 2000. p.15-37.

KRAYCHETE, Gabriel; LARA, Francisco ; COSTA, Beatriz (orgs.). Economia dos Setores Populares: entre a realidade e a utopia. Petrópolis: Vozes; Rio de Janeiro: Capina; Salvador: CESE e U CSAL, 2000.

JOHNSON, Monica K. Social origins, adolescent experiences, and work value trajectories during the transition to adulthood. Social Forces, Chapel Hill, vol. 80, n 4, p.1307-1341, 2002. Disponível em: http://www.periodicos.capes.gov.br. 
LAVILLE, Jean-Louis (org.). Economía Social y Solidaria: una visión europea. Buenos Aires: Altamira, 2004.

LIMA, Jacob Carlos. As artimanhas da flexibilização: o trabalho terceirizado em cooperativas de produção. São Paulo: Terceira M argem, 2002.

LISBO A, Armando de M elo. Solidariedade. In: CATTANI, Antonio D. (org.). A outra economia. Porto Alegre: Veraz Editores, 2003. pp.242-250.

LINDSAY, Paul ; KNOX, William E. Continuity and change in work values among young adults: a longitudinal study. American Journal of Sociology, Chicago, vol. 89, $\mathrm{n}^{\circ} 4, \mathrm{p} .918-931,1984$.

M ANCE, Euclides A. A Revolução das Redes: a colaboração solidária como uma alternativa pós-capitalista à globalização atual. Petrópolis: Vozes, 1999.

MORTIM ER, Jeylan T. ; LO REN CE, Jon. Work experience and occupational value socialization: a longitudinal study. American Journal of Sociology, Chicago, vol. $84, n^{\circ} 6, p .1361-1385,1979$.

PINHO, Diva B. 0 Cooperativismo no Brasil: da Vertente Pioneira à Vertente Solidária. São Paulo: Saraiva, 2004.

RAZETO, Luis. Los Caminos de la Economía de Solidaridad. Buenos Aires: LU M ENHVM ANITAS, 1997.

SALAM O N, Lester M . ; AN HEIER, H elmut K. The civil society sector. Society, v.34, n.2, p.60-66, 1997. Disponível em: <www. periodicos.capes.gov.br>.

SCHÖNPFLUG, Ute. Intergenerational transmission of values: the role of transmission belts. Journal of Cross-Cultural Psychology, Thousands 0 aks, vol. 32, n², p.174-185, 2001. Disponível em: http://www. periodicos.capes.gov.br.

SELIGER, Martin. Ideology and Politics. New York: The Free Press, 1976.

SINGER, Paul. Uma utopia militante: repensando o socialismo. 2ª ed. Petrópolis: Vozes, 1999.

. Economia solidária: um modo de produção e distribuição. In: SINGER, Paul ; S̄ŌUZA, André R. (orgs.). A Economia Solidária no Brasil: a autogestão como resposta ao desemprego. São Paulo: Contexto, 2000a. pp.11-28.

. Economia dos setores populares: propostas e desafios. In: KRAYCHETE, Gabriel; LARA. Francisco ; CO STA, Beatriz (orgs.). Economia dos setores populares: entre a realidade e a utopia. Petrópolis: Vozes; Rio de Janeiro: Capina; Salvador: CESE e UCSAL, 2000b. pp.143-161. $\overline{2} \overline{0} 2 \mathrm{a}$.

Introdução à Economia Solidária. São Paulo: Fundação Perseu Abramo, 
- A recente ressurreição da economia solidária no Brasil. In: SANTOS, Boaventura de Sousa (org.). Produzir para viver: os caminhos da produção não capitalista. Rio de Janeiro: Civilização Brasileira, 2002b. pp.81-129.

. Globalização e Desemprego. 6ạ ed. São Paulo: Contexto, 2003.

. Prefácio: um olhar diferente sobre a Economia Solidária. In: FRANÇA FILHO, Genauto ; LAVILLE, Jean-Louis. Economia Solidária: uma abordagem internacional. Porto Alegre: UFRGS, 2004. pp.5-9.

Recebido: 16/03/2007

Aceite final: 24/06/2008 